\title{
Atividade alelopática de caju-de-árvore-do-cerrado sobre a germinação e crescimento de alface e rabanete
}

\author{
Allelopathic activity of "caju-de-árvore-do-cerrado" on lettuce and radish germination and growth \\ Actividad alelopática de "caju-de-árvore-do-cerrado" sobre la germinación y crecimiento de
} lechugas y rábanos

Recebido: 20/11/2020 | Revisado: 02/12/2020 | Aceito: 12/01/2021 | Publicado: 13/01/2021

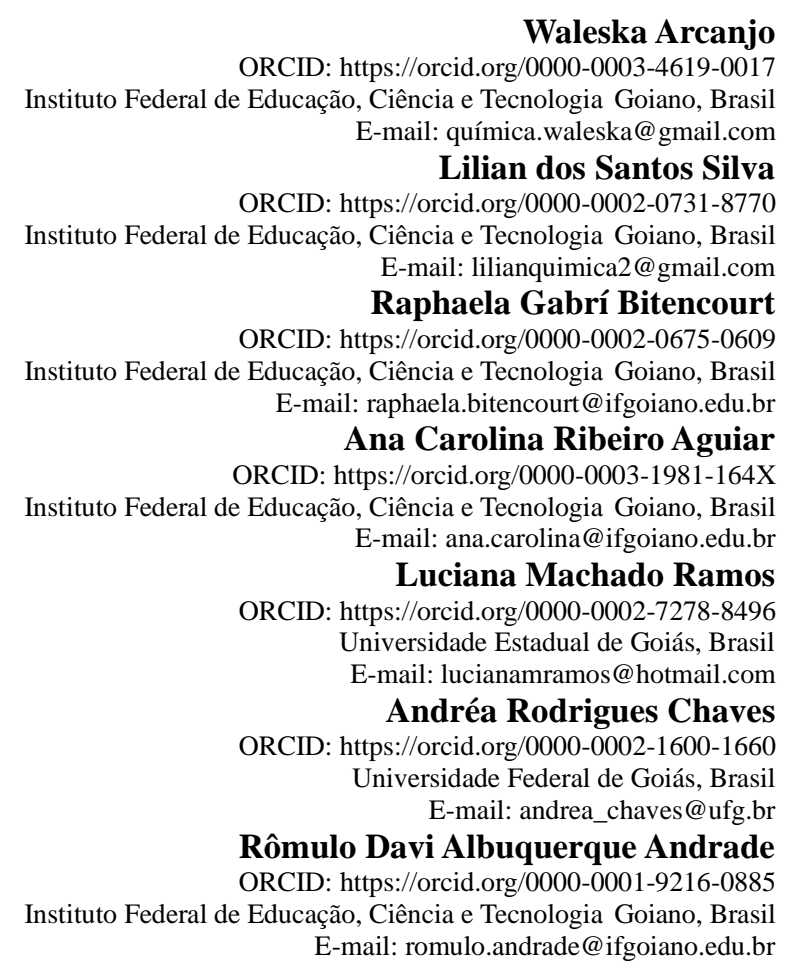

\section{Resumo}

O estudo da atividade alelopática vem sendo utilizado no combate e controle de doenças, insetos e plantas daninhas. Este trabalho teve por objetivo avaliar o efeito alelopático de extratos das folhas de caju-de-árvore-do-cerrado (Anacardium othonianum Rizz.) na germinação e no crescimento inicial de plântulas de alface (Lactuca sativa L.) e rabanete (Raphanus sativus L.). Inicialmente, foram obtidos extratos aquosos das folhas da planta in natura por dois métodos de extração aquosa: infusão e decocção. Os bioensaios de germinação e crescimento de alface e rabanete foram realizados em triplicata, com tratamentos compostos por seis diferentes diluições dos extratos, sendo feita a análise da porcentagem de germinação, comprimento de radículas e da parte aérea das plântulas após 7 dias de incubação, sob condições de temperatura e luz artificiais. Verificou-se a existência do potencial alelopático em ambos os extratos das folhas de caju-de-árvore-do-cerrado, pela sensibilidade observada nas sementes de alface e rabanete. Além disso, constatou-se que os efeitos dos aleloquímicos são dependentes da dosagem utilizada, já que foram observadas variações nos efeitos alelopáticos (inibitório e/ou estimulante) apenas alterando a concentração aplicada dos extratos.

Palavras-chave: Plântula; Extrato aquoso; Anacardium othonianum rizz.

\begin{abstract}
Allelopathic activity study has been used to combat and control diseases, insects and weeds. This work aimed to evaluate the allelopathic effect of extracts from caju-de-árvore-do-cerrado (Anacardium othonianum) leaves on germination and initial growth of lettuce (Lactuca sativa L.) and radish (Raphanus sativus L.) seedlings. Initially, aqueous extracts from in natura leaves were obtained by two methods of aqueous extraction: infusion and decoction. The lettuce and radish germination and growth bioassays were carried out in triplicate, with treatments consisting of six different dilutions of the extracts, analyzing the germination percentage, root length and seedlings aerial-part length after 7 days of incubation, under artificial temperature and light conditions. The allelopathic potential was
\end{abstract}


verified in both extracts of caju-de-árvore-do-cerrado leaves, due to the sensitivity observed in the lettuce and radish seeds. In addition, it was observed that the effects of allelochemicals are dependent on the dosage, since variations in allelopathic effects (inhibitory and/ or stimulating) were observed when changing the concentration of the extracts applied.

Keywords: Seedling; Aqueous extract; Anacardium Othonianum.

\section{Resumen}

El estudio de la actividad alelopática se ha utilizado para combatir y controlar enfermedades, insectos y malas hierbas. El objetivo de este trabajo fue evaluar el efecto alelopático de extractos de hojas de caju-de-árvore-do-cerrado (Anacardium othonianum Rizz.) sobre la germinación y crecimiento inicial de plántulas de lechuga (Lactuca sativa L.) y rábano (Raphanus sativus). L.). Inicialmente, los extractos acuosos de las hojas de la planta in natura se obtuvieron mediante dos métodos de extracción acuosa: infusión y decocción. Los bioensayos de germinación y crecimiento de lechuga y rábano se realizaron por triplicado, con tratamientos que consistieron en seis diluciones diferentes de los extractos, con el análisis del porcentaje de germinación, longitud de raíz y brote de plántula a los 7 días de incubación, en condiciones de luz y temperatura artificial. Se verificó la existencia del potencial alelopático en ambos extractos de las hojas de caju-de-árvore-do-cerrado, debido a la sensibilidad observada en las semillas de lechuga y rábano. Además, se encontró que los efectos de los aleloquímicos dependen de la dosis utilizada, ya que las variaciones en los efectos alelopáticos (inhibidores y/o estimulantes) se observaron solo cambiando la concentración aplicada de los extractos.

Palabras clave: Plántula; Extracto acuoso; Anacardium othonianum rizz.

\section{Introdução}

O campo da agricultura contribui significativamente para o crescimento da economia do Brasil, e o país se destaca no cenário da agricultura mundial. Porém, com a ampliação da área agrícola, os produtores almejam e visam o desenvolvimento de culturas que tragam altas produtividade e rentabilidade. Para atingir esses objetivos, entretanto, é necessário fazer uso de produtos que ajudem a proteger a cultura de pragas que possam prejudicar seu desenvolvimento. Com isso, se observa um grande aumento no uso de defensivos agrícolas (herbicidas, fungicidas, inseticidas, nematicidas e outros) e de agroquímicos (fertilizantes e corretivos) nas lavouras, o que pode provocar contaminações ambientais trazendo impactos inesperados e desastrosos ao meio ambiente (Paracampo et al., 2009, Pessanha et al., 2010).

Visando diminuir o uso de defensivos agrícolas nas lavouras, se observa um aumento pelo interesse de diversos pesquisadores em desenvolver métodos sustentáveis que possam minimizar o impacto ambiental desses compostos sobre a qualidade da água, do solo e do ar. Neste contexto, buscam-se técnicas alternativas e menos poluentes que possam se tornar opções mais racionais na exploração agrícola. Dentre essas alternativas, destaca-se o fenômeno da alelopatia como uma proposta para o controle de doenças e insetos e para a redução no uso de herbicidas (Silva \& Carvalho, 2009; Pessanha et al., 2010).

A alelopatia pode ser definida como um processo natural da planta que produz metabólitos secundários, que podem exercer efeitos de inibição ou estímulo no crescimento e desenvolvimento de outras plantas e outros organismos (Rice, 1984; Silva \& Carvalho, 2009; Maraschin \& Alves-Áquila, 2005). Visando reduzir o uso de agrotóxico e a adoção de uma agricultura sustentável, tem-se elevado o número de pesquisas em busca por plantas com potenciais inseticidas, herbicidas, entre outros.

O estudo sobre a atividade alelopática já foi verificado por diversos autores em diferentes espécies de plantas. Carmo et al. (2007) constataram atividade alelopática utilizando extratos aquosos da casca do tronco e de raízes de canela-sassafrás (Ocotea odorifera) que causaram diminuição do sistema radicular nas plântulas de sorgo (Sorghum bicolor L.). Gusman et al. (2008) verificaram efeito alelopático nos extratos aquosos de folhas secas de alecrim-do-campo (Baccharis dracunculifolia DC.) através da redução do percentual de germinação de todas espécies testadas (mostarda, repolho, melancia, rúcula, cultivares de alface, tomate, rabanete e milho). Borella \& Pastorini (2010) utilizaram os extratos aquosos dos frutos frescos de umbu (Phytolacca dioica L.) verificando uma interação significativa na porcentagem de germinação, velocidade de germinação e índice de velocidade de germinação, obtendo-se efeitos mais significativos na germinação de sementes de picão- 
preto (Bidens pilosa L.) do que na germinação de sementes de alface (Lactuca sativa L. cv. Grand rapidis). Por fim, extratos etanólicos de folhas de Anacardium humilee também tiveram seu efeito alelopático verificado (Pereira et al., 2018b).

A espécie Anacardium othonianum Rizz. destaca-se dentre as espécies encontradas no Cerrado brasileiro devido à importância econômica para região em que se encontra quando comparada com outras espécies nativas do Cerrado (AgostiniCosta et al., 2006; Silva, 2010). Esta espécie pertence à família Anacardiaceae e é conhecida popularmente como caju-deárvore-do-cerrado, cajuzinho e cajuí. O uso desta espécie é bastante difundido na medicina popular, apresentando ação antiinflamatória, antidiarreica, expectorante, anti-sifilítica e estimulante, podendo ser utilizada para tratar diabetes e reumatismo (Silva, 2010; Souza et al., 2010).

Dessa forma, A. othonianum possui um grande potencial de herbicida natural, porém o efeito alelopático desta espécie nunca foi verificado sobre plantas. A literatura sobre essa espécie ainda é escassa, sendo de grande importância o estudo do efeito alelopático causado por ela. Dessa forma, este trabalho tem por finalidade analisar o efeito alelopático de extratos aquosos das folhas da planta A. othonianum, sobre a germinação e crescimento de plântulas de alface (Lactuca sativa $\mathrm{L}$.) e rabanete (Raphanus sativus L.).

\section{Metodologia}

A metodologia utilizada neste trabalho tem natureza quantitativa, através da qual fez-se a coleta de dados numéricos por meio do uso de medições de grandezas, sendo estas posteriormente analisadas estatisticamente, o que permite a análise do problema e previsão de acontecimentos (Pereira et al., 2018a).

Foram utilizadas amostras de folhas frescas de caju-de-árvore-do-cerrado (A. othonianum), que foram coletadas no Instituto Federal Goiano - Campus Rio Verde. O material vegetal fresco foi triturado em moinho de facas e posteriormente submetido a dois métodos de extração utilizando como solvente apenas água destilada. Os métodos utilizados para extração foram a infusão (I) e a decocção (D).

Para a obtenção do extrato por infusão, $100 \mathrm{~mL}$ de água destilada, aquecida previamente a $100{ }^{\circ} \mathrm{C}$, foram adicionados a $10 \mathrm{~g}$ do material vegetal triturado. A mistura permaneceu em contato por 15 minutos e em seguida foi realizada uma filtração simples para a separação do material vegetal e do extrato bruto. O extrato bruto obtido foi diluído com água destilada na proporção de 1:10 v/v para obter diluições de $10^{-1}$ a $10^{-6}$ extrato bruto/água.

Para o procedimento de decocção, $10 \mathrm{~g}$ do material vegetal triturado foram misturados com $100 \mathrm{~mL}$ de água destilada e, em seguida, a mistura foi aquecida a $100{ }^{\circ} \mathrm{C}$ utilizando uma chapa de aquecimento através da qual se promoveu o controle da temperatura. $\mathrm{O}$ aquecimento foi mantido por 15 minutos e, na sequência, a suspensão foi filtrada para separação do extrato bruto e do material vegetal. De forma similar ao realizado com o extrato obtido por infusão, promoveu-se a diluição do extrato bruto com água destilada na proporção de 1:10 v/v para obter diluições de $10^{-1}$ a $10^{-6}$ extrato bruto/água.

Os bioensaios de germinação e crescimento de plântulas de alface (Lactuca sativa L.) e rabanete (Raphanus sativus L.) para análise da atividade alelopática dos extratos foram conduzidos no laboratório de Águas e Efluentes do Instituto Federal Goiano - Campus Rio Verde, em capela de fluxo laminar vertical, utilizando materiais previamente limpos e esterilizados em autoclave.

As sementes das plantas-testes foram adquiridas no comércio local de Rio Verde - GO, da marca Feltrin. As sementes de alface utilizadas foram da variedade "Repolhuda todo ano" e as de rabanete foram da variedade "Crimson Gigante". Para a realização dos experimentos, as sementes foram germinadas em placas de petri contendo disco de papel de filtro como suporte (Brasil, 2009). O papel foi umedecido com 3,0 mL dos extratos aquosos obtidos por infusão (I) e decocção (D) de folhas cajude-árvore-do-cerrado, em diferentes concentrações $\left(10^{-1}, 10^{-2}, 10^{-3}, 10^{-4}, 10^{-5}\right.$ e $\left.10^{-6}\right)$ preparadas por diluição seriada em água, como mostra a Figura 1. Para o controle foi utilizado apenas água destilada estéril para umidificar o papel de filtro. 
Figura 1. Diagrama esquemático do procedimento experimental para avaliação da atividade alelopática de extratos de folhas de caju-de-árvore-do-cerrado em diferentes concentrações sobre a germinação e crescimento de alface (placa A) e rabanete (placa R).

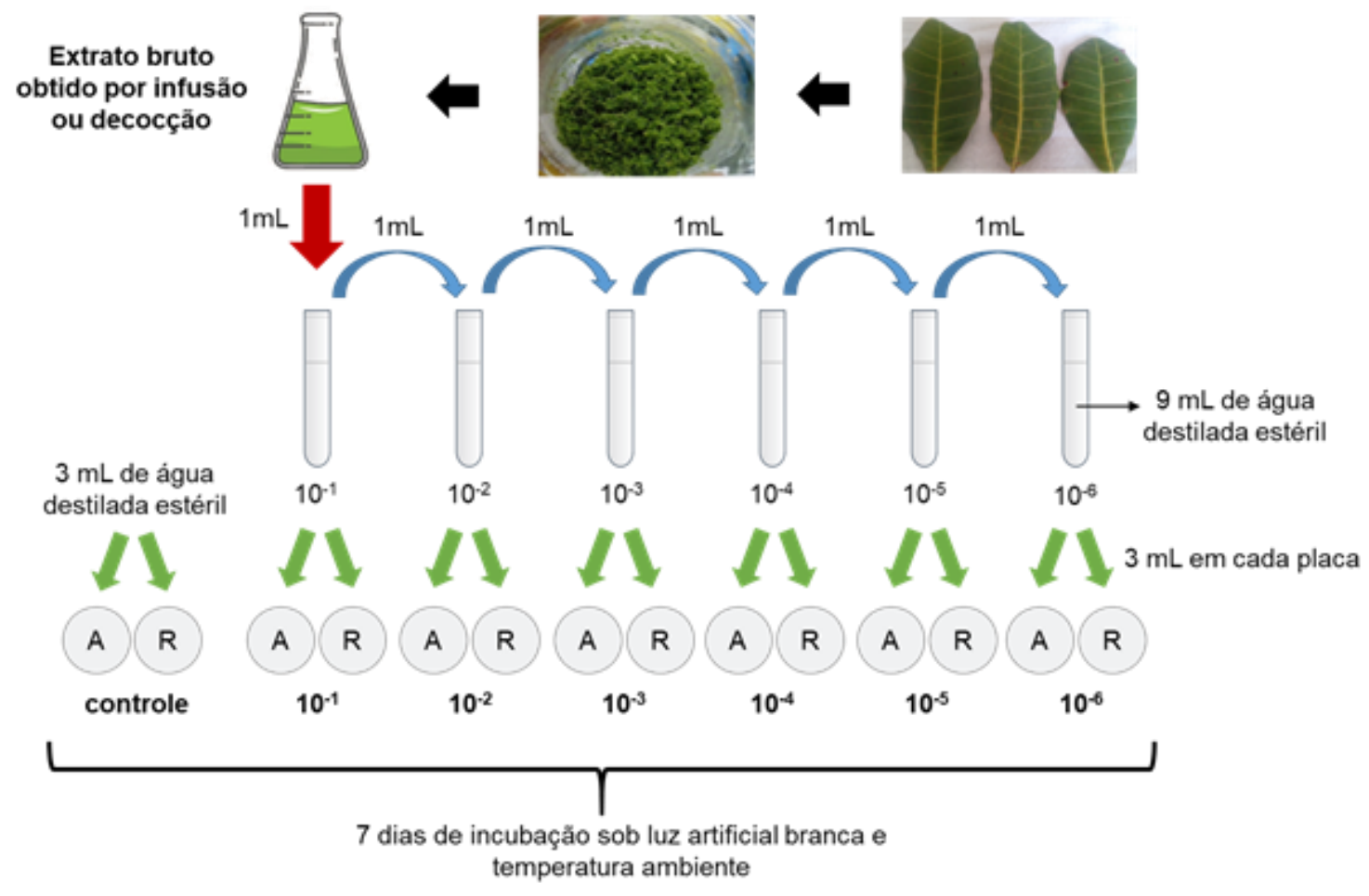

Fonte: Autores.

Foram utilizadas 15 sementes de alface em cada placa (placa A) e 5 sementes de rabanete (placa R), sendo 3 repetições para cada tratamento, totalizando 39 placas analisadas para cada tipo de semente (18 placas para análise do extrato obtido por infusão, 18 placas para extrato obtido por decocção e 3 placas para o controle).

As placas, em seguida, foram vedadas com o filme plástico (PVC) para evitar a evaporação da água e mantidas sob luz artificial (branca e fria) constante a temperatura ambiente $\left(28\right.$ a $\left.32{ }^{\circ} \mathrm{C}\right)$ por 7 dias, segundo recomendações de Brasil (1992), a fim de favorecer a germinação das sementes. Após esse período de incubação, foi realizada a avaliação da porcentagem de germinação e a determinação do comprimento da radícula e da parte aérea das plântulas (Brasil, 1992). A porcentagem de germinação foi calculada simplesmente pela razão entre o número de sementes germinadas e o número de sementes na amostra (multiplicada por 100).

Os resultados obtidos foram submetidos a análises estatísticas de comparação de médias pelo teste Tukey com $5 \%$ de significância, utilizando os softwares Origin Pro 8 e SISVAR (Ferreira, 1999). Além disso, foi utilizada a estatística descritiva considerando a correlação de Pearson, que pode ser usado para medir a força, a intensidade ou o grau de relação linear, entre duas variáveis.

\section{Resultados e Discussão}

Os resultados da média da porcentagem de germinação em sementes de alface e de rabanete tratadas com os extratos aquosos das folhas frescas de caju-de-árvore-do-cerrado, obtidos pelos métodos de infusão e decocção em diferentes diluições são apresentados na Tabela 1. 
Tabela 1. Porcentagem de germinação em sementes de alface e de rabanete, submetidas a diferentes concentrações de extrato aquoso de caju-de-árvore-do-cerrado obtidos por método de infusão (I) e decocção (D)*

\begin{tabular}{ccccc}
\hline \multirow{2}{*}{ Diluição } & \multicolumn{2}{c}{ Alface } & \multicolumn{2}{c}{ Rabanete } \\
\cline { 2 - 5 } & Infusão & Decocção & Infusão & Decocção \\
\hline Controle & $15,0 \mathrm{a}$ & $15,0 \mathrm{a}$ & $5,0 \mathrm{a}$ & $5,0 \mathrm{a}$ \\
$10^{-1}$ & $13,6 \mathrm{a}$ & $12,6 \mathrm{~b}$ & $4,6 \mathrm{a}$ & $4,6 \mathrm{a}$ \\
$10^{-2}$ & $14,6 \mathrm{a}$ & $14,3 \mathrm{a}$ & $5,0 \mathrm{a}$ & $5,0 \mathrm{a}$ \\
$10^{-3}$ & $14,6 \mathrm{a}$ & $14,3 \mathrm{a}$ & $5,0 \mathrm{a}$ & $4,6 \mathrm{a}$ \\
$10^{-4}$ & $14,3 \mathrm{a}$ & $14,6 \mathrm{a}$ & $4,6 \mathrm{a}$ & $5,0 \mathrm{a}$ \\
$10^{-5}$ & $14,3 \mathrm{a}$ & $14,6 \mathrm{a}$ & $4,6 \mathrm{a}$ & $5,0 \mathrm{a}$ \\
$10^{-6}$ & $13,6 \mathrm{a}$ & $14,3 \mathrm{a}$ & 0,078 & $4,3 \mathrm{a}$ \\
\hline Coeficiente de variação & 0,06 & 0,05 & 0,37 & 0,078 \\
\hline Correlação de Pearson & 0,26 & 0,44 & 0,29 \\
\hline
\end{tabular}

*Médias seguidas da mesma letra na mesma coluna não diferem entre si estatisticamente pelo o teste de Tukey ao nível de significância de $5 \%$.

Fonte: Autores.

Para avaliação da germinação, as sementes de alface e rabanete tratadas com os extratos diluídos das folhas frescas de caju-de-árvore-do-cerrado foram comparadas com as sementes tratadas com água destilada (controle). Pela análise estatística é possível observar que não há alterações significativas na germinação da maioria das sementes de alface (Lactuca sativa L.) e de rabanete (Raphanus sativus L.).

O único efeito inibitório significativo observado ocorreu na diluição $10^{-1}$ do extrato obtido por decocção quando adicionado às sementes de alface. A alface tem sido amplamente utilizada para ensaios alelopáticos devido à sua alta sensibilidade e rápida germinação (Ding et al., 2008). O efeito inibitório observado deve estar relacionado com a quantidade do metabólito extraído já que foi observado apenas na menor diluição realizada. Além disso, este resultado também evidencia que o método de extração utilizado influencia nos metabólitos extraídos, uma vez que este comportamento foi observado apenas para o extrato obtido por decocção.

Resultados semelhantes foram observados por Periotto et al. (2004) estudando o efeito alelopático da Andira humilis Mart. ex Benth na germinação da alface e rabanete. Os autores utilizaram extratos aquosos de plantas adultas de Andira humilis Mart. ex Benth em diferentes diluições e observaram que o extrato mais concentrado (16\% m/v) produziu efeito inibitório significativo na porcentagem de germinação da alface e do rabanete e nas demais diluições este efeito não foi constatado.

Outro trabalho, realizado por Ding et al. (2008), evidencia a influência da concentração do metabólito no crescimento da raiz da alface (Lactuca sativa L.). Nesse trabalho, os autores avaliaram o crescimento da raiz em diferentes concentrações de Leukamenin E, um diterpenóide isolado da espécie Isodon racemosa (Hemsl) Hara, e observaram um efeito inibitório significativo em concentrações acima de $50 \mu \mathrm{M}$, sendo este efeito mais intenso na maior concentração utilizada (200 $\mu \mathrm{M})$.

A Tabela 2 apresenta os resultados obtidos para a avaliação dos comprimentos da radícula e do folículo de plântulas de alface submetidas aos tratamentos com os extratos obtidos por infusão e decocção. 
Tabela 2. Comprimento da radícula e do folículo de plântulas de alface, quando submetidas ao tratamento com diferentes concentrações de extratos aquosos de caju-de-árvore-do-cerrado obtidos pelos métodos de infusão (I) e decocção (D)*.

\begin{tabular}{ccccc}
\hline \multirow{2}{*}{ Diluição } & \multicolumn{2}{c}{ Alface (I) } & \multicolumn{2}{c}{ Alface (D) } \\
\cline { 2 - 5 } & Radícula $(\mathrm{cm})$ & Aérea $(\mathrm{cm})$ & Radícula $(\mathrm{cm})$ & Aérea $(\mathrm{cm})$ \\
\hline Controle & $2,86 \mathrm{bc}$ & $2,06 \mathrm{~b}$ & $2,86 \mathrm{a}$ & $2,06 \mathrm{a}$ \\
$10^{-1}$ & $0,39 \mathrm{e}$ & $1,77 \mathrm{c}$ & $0,17 \mathrm{~d}$ & $1,44 \mathrm{c}$ \\
$10^{-2}$ & $2,51 \mathrm{~cd}$ & $2,14 \mathrm{~b}$ & $1,92 \mathrm{c}$ & $2,27 \mathrm{ab}$ \\
$10^{-3}$ & $2,08 \mathrm{~d}$ & $2,20 \mathrm{~b}$ & $2,27 \mathrm{bc}$ & $2,17 \mathrm{a}$ \\
$10^{-4}$ & $3,04 \mathrm{ab}$ & $2,24 \mathrm{~b}$ & $2,70 \mathrm{a}$ & $2,15 \mathrm{a}$ \\
$10^{-5}$ & $3,48 \mathrm{a}$ & $2,53 \mathrm{a}$ & $2,59 \mathrm{ab}$ & $2,28 \mathrm{ab}$ \\
$10^{-6}$ & $2,54 \mathrm{~cd}$ & $2,21 \mathrm{~b}$ & $2,87 \mathrm{a}$ & $2,43 \mathrm{~b}$ \\
\hline Coeficiente de variação & 0,56 & 0,31 & 0,53 & 0,28 \\
Correlação de Pearson & $3,08 \times 10^{-4}$ & $5,53 \times 10^{-4}$ & $5,61 \times 10^{-5}$ & $5,18 \times 10^{-6}$ \\
\hline
\end{tabular}

*Médias seguidas da mesma letra na mesma coluna não diferem entre si estatisticamente pelo o teste de Tukey ao nível de significância de $5 \%$.

Fonte: Autores.

Nas amostras tratadas com extrato de diluição $10^{-1}$ foi observada inibição significativa no crescimento tanto da radícula quanto do folículo, quando se utilizou os extratos obtidos pelos dois métodos. Este efeito inibitório intenso, de 86,3\% na radícula tratada com o extrato obtido por infusão e de 94,0\% na radícula tratada com o extrato obtido por decocção, só é observado para esta diluição. O comprimento da parte aérea da plântula de alface também diminuiu em função do tratamento com o extrato diluído a $10^{-1}$, entretanto, neste caso, a inibição foi menos acentuada: 14,0\% quando as sementes de alface foram submetidas ao tratamento por infusão e $30,1 \%$ quando submetidas ao tratamento por decocção.

Rosado et al. (2009) também observaram efeitos inibitórios no comprimento das raízes de sementes de melissa (Melissa officinalis L.) quando tratadas com extrato aquoso de manjericão (Ocimum basilicum L). Neste trabalho os autores utilizaram o extrato aquoso de manjericão nas concentrações de 0,$001 ; 0,01 ; 0,1$ e $1,0 \%$ (v/v) e foi observado que ao utilizar a dose de $1 \%$, a melissa apresentou o menor comprimento da raiz evidenciando o efeito alelopático nesta condição.

Os tratamentos da radícula da plântula de alface com as diluições $10^{-2}$ e $10^{-3}$ dos extratos aquosos obtidos por decocção, também apresentaram efeito inibitório, sendo essa inibição respectivamente de 32,8\% e 20,6\%. Já nos extratos aquosos obtidos por infusão nas mesmas diluições se observou diminuição de, respectivamente, 12,2\% e 27,3\% no comprimento da radícula da plântula de alface, quando comparado com o controle. Entretanto, como é possível observar na Tabela 2, essa inibição foi inferior àquela observada com o tratamento da diluição $10^{-1}$.

Resultados semelhantes foram observados por Rickli et al. (2011), onde o extrato aquoso das folhas de Nim (Azadirachta indica A. Juss) exerceu efeito inibitório no comprimento médio de raiz da plântula de milho (Zea mays L.) apresentando alterações significativas a partir da concentração de $20 \%$, onde se observou comprimentos inferiores ao controle.

As concentrações $10^{-4}$ e $10^{-5}$ do extrato aquoso de caju-de-árvore-do-cerrado, submetidos ao tratamento infusão (Tabela 2), apresentaram efeito estimulante no crescimento das plântulas de alface, acarretando um crescimento de respectivamente $6,3 \%$ e $21,7 \%$ no comprimento da radícula de alface, quando comparado com o controle. Este resultado sugere a presença de um ou mais compostos bioestimulantes nestes extratos e remete à possibilidade de avaliações através do isolamento destes compostos.

Este efeito estimulante também foi observado no crescimento da parte aérea da plântula de alface, quando tratada com o extrato obtido por infusão. Neste caso, obteve-se um aumento de $22,8 \%$ utilizando a diluição $10^{-5}$. Já a plântula de alface 
tratada com os extratos obtidos por decocção apresentou acréscimo significativo, de 17,9\% no comprimento da parte aérea, apenas quando se utilizou a diluição $10^{-6}$.

Os resultados obtidos para o crescimento da radícula e da parte aérea das plântulas de rabanete, submetidas aos tratamentos com os extratos de folhas de caju-de-árvore-do-cerrado obtidos por infusão e decocção, são apresentados na Tabela 3.

Tabela 3. Comprimento da radícula e do folículo de plântulas de rabanete, quando submetidas ao tratamento com diferentes concentrações de extratos aquosos de caju-de-árvore-do-cerrado obtidos pelos métodos de infusão (I) e decocção (D)*.

\begin{tabular}{ccccc}
\hline \multirow{2}{*}{ Diluição } & \multicolumn{2}{c}{ Rabanete $(\mathbf{I})$} & \multicolumn{2}{c}{ Rabanete $(\mathbf{D})$} \\
\cline { 2 - 5 } & Radícula $(\mathrm{cm})$ & Aérea $(\mathrm{cm})$ & Radícula $(\mathrm{cm})$ & Aérea $(\mathrm{cm})$ \\
\hline Controle & $9,08 \mathrm{a}$ & $5,18 \mathrm{a}$ & $9,08 \mathrm{a}$ & $5,18 \mathrm{a}$ \\
$10^{-1}$ & $-* *$ & $-* *$ & $-* *$ & $-* *$ \\
$10^{-2}$ & $4,80 \mathrm{c}$ & $4,22 \mathrm{bc}$ & $6,47 \mathrm{ab}$ & $4,61 \mathrm{a}$ \\
$10^{-3}$ & $4,68 \mathrm{c}$ & $3,52 \mathrm{c}$ & $5,68 \mathrm{~b}$ & $4,86 \mathrm{a}$ \\
$10^{-4}$ & $6,81 \mathrm{bc}$ & $4,97 \mathrm{ab}$ & $7,01 \mathrm{ab}$ & $5,21 \mathrm{a}$ \\
$10^{-5}$ & $8,23 \mathrm{ab}$ & $5,38 \mathrm{a}$ & $8,03 \mathrm{ab}$ & $4,58 \mathrm{a}$ \\
$10^{-6}$ & $6,15 \mathrm{bc}$ & $4,52 \mathrm{ab}$ & $8,84 \mathrm{ab}$ & $5,96 \mathrm{a}$ \\
\hline Coeficiente de variação & 0,48 & 0,29 & 0,38 & 0,25 \\
\hline Correlação de Pearson & 0,076 & $7,42 \times 10^{-4}$ & 0,011 & $3,33 \times 10^{-4}$ \\
\hline
\end{tabular}

*Médias seguidas da mesma letra na mesma coluna não diferem entre si estatisticamente pelo o teste de Tukey ao nível de significância de $5 \%$.

**Não foi possível realizar a medição.

Fonte: Autores.

As plântulas de rabanete tratadas com o extrato mais concentrado $\left(10^{-1}\right)$ apresentaram anormalidade em seu crescimento, não resistindo à presença do extrato e apresentando completo apodrecimento após o período de 7 dias, impedindo a medida do comprimento, tanto da radícula quanto da parte aérea da plântula.

Gatti et al. (2003) também verificaram anormalidade no sistema radicular no crescimento de plântulas de alface e rabanete que foram tratadas com o extrato aquoso da raiz de Aristolochia esperanzae O. Kuntze (jarrinha) na concentração $100 \%$. Algumas plântulas apresentaram raízes curtas e desproporcionais em relação às outras estruturas da planta e nas plântulas de alface o tratamento com o extrato concentrado provocou a morte de todas as plântulas, que se apresentaram apodrecidas.

Analisando os comprimentos da radícula das plântulas de rabanete (Tabela 3) é possível observar que todas as concentrações dos extratos aquosos de folhas de caju-de-árvore-do-cerrado utilizados acarretaram a inibição do crescimento da radícula, independente do método de extração utilizado.

Neste caso, as diluições $10^{-2}$ e $10^{-3}$ destacam-se apresentando as inibições mais significativas no comprimento da radícula, onde se observa inibição de $55,1 \%$ e $48,5 \%$, respectivamente, para a plântula de rabanete tratado pelo método infusão. Já para as sementes de rabanete tratadas com o extrato obtido por decocção nas mesmas concentrações $\left(10^{-2}\right.$ e $\left.10^{-3}\right)$ foi observada uma diminuição no crescimento da radícula de, respectivamente, $28,7 \%$ e 37,4\%, quando comparado ao controle.

Os resultados obtidos neste trabalho vão de acordo com os conceitos propostos por Reigosa et al. (1999), que estabeleceram que os efeitos alelopáticos de uma espécie nos diferentes processos fisiológicos de uma planta são dependentes de diversos fatores incluindo concentração, temperatura e muitas outras circunstâncias ambientais que podem ocorrer 
simultaneamente.

Em relação ao coeficiente de correlação de Pearson, foi observado que os extratos aquosos em diferentes diluições de caju-de-árvore-do-cerrado utilizados na germinação das plântulas de alface e rabanete apresentaram correlações positivas, indicando que existe um efeito indireto atuando sobre a germinação dessas plântulas. Esse efeito indireto foi, para todos os casos, positivo para correlações próximas de |1|. Porém pode-se observar que o efeito alelopático dos extratos aquosos de folhas de caju-de-árvore-do-cerrado sobre crescimento da radícula e da parte aérea das plântulas de alface e rabanete possui uma baixa tendência, ou seja, é difícil obter estimativas da correlação linear de Pearson com elevada precisão, especialmente, para pares de caracteres com baixa intensidade de relação linear, em função da ação das diferentes diluições dos extratos aquosos sobre as sementes das espécies estudadas.

É importante salientar que não são encontrados na literatura científica trabalhos que avaliam o efeito alelopático dos extratos aquosos de folhas de caju-de-árvore-do-cerrado (Anacardium othonianum Rizz.) sobre a germinação e crescimento de plântulas de alface e rabanete.

\section{Conclusões}

A pesquisa experimental desenvolvida permitiu verificar a existência do potencial alelopático dos extratos obtidos das folhas de caju-de-árvore-do-cerrado, pela sensibilidade observada nas sementes de alface e rabanete. Estas espécies foram utilizadas por serem indicadoras da presença de aleloquímicos, o que se pode constatar tanto nos extratos obtidos por infusão quanto por decocção. Além disso, constatou-se que os efeitos dos aleloquímicos são dependentes da dosagem utilizada, já que foram observadas variações nos efeitos alelopáticos (efeito inibitório e/ou estimulante) apenas alterando a concentração utilizada dos extratos.

A alelopatia é uma área de grande importância para a germinação e crescimento inicial de sementes e estudos adicionais considerando a caracterização química dos princípios ativos presentes nos extratos aquosos de folhas de caju-deárvore-do-cerrado podem proporcionar esclarecimento sobre os efeitos fisiológicos dos mesmos. Por fim, os efeitos alelopáticos apresentados neste trabalho mostram que esta espécie apresenta grande potencial para verificação dos metabólitos presentes em seus extratos e suas possíveis aplicações para diversas áreas de estudos.

\section{Agradecimentos}

À Coordenação de Aperfeiçoamento de Pessoal de Nível Superior (Capes) pela concessão da bolsa de mestrado, ao Professor Dr. Rômulo Davi Albuquerque Andrade pelo auxílio em todas as etapas do trabalho e por disponibilizar o laboratório para realização do mesmo e ao Instituto Federal Goiano - Campus Rio Verde.

\section{Referências}

Agostini-Costa, T. S., Faria, J. P., Naves, R. V., \& Vieira, R. F. Cajus do Cerrado. In: Vieira, R. F., Agostini-Costa, T. S., Silva, D. B., Ferreira, F. R., \& Sano, S. M. (2006). Frutas Nativas da Região Centro-Oeste do Brasil. Brasília: Embrapa Recursos Genéticos e Biotecnologia. 8, $136-151$.

Borella, J., \& Pastorini, L. H. (2010). Efeito alelopático de frutos de umbu (Phytolacca dioica L.) sobre a germinação e crescimento inicial de alface e picãopreto. Revista Ciência e Agrotecnologia, 34, 1129-1135.

Carmo, F. M. S., Borges, E. E. L., \& Takaki, M. (2007). Alelopatia de extratos aquosos de canela-sassafrás (Ocotea odorifera (Vell.) Rohwer). Acta Botânica Brasílica, 21, 697-705.

Ding, L., Qi, L., Jing, H., Li, J., Wang, W., \& Wang, T. (2008). Phytotoxic effects of leukamenin E (an ent-kaurene diterpenoid) on root growth and root hair development in Lactuca sativa L. seedlings. Journal of Chemical Ecology, 34, 1492-500.

Ferreira, D. F. (1999). Sistema Para análise de variância para dados balanceados (SISVAR): UFLA; 92p.. 
Gatti, A. B., Perez, S. C. J. G. A., \& Lima, M. I. S. (2004). Atividade alelopática de extratos aquosos de Aristolochia esperanzae O. Kuntze na germinação e no crescimento de Lactuca sativa L. e Raphanus sativus L. ACTA Botânica Brasílica, 18(3), 459-472.

Gusman, G. S., Bittencourt, A. H. C., \& Vestena, S. (2008). Alelopatia de Baccharis dracunculifolia DC. sobre a germinação e desenvolvimento de espécies cultivadas. Acta Scientiarum. Biological Sciences, 30, 119-125.

Maraschin-Silva, F., \& Aquila, M. E. A. (2005). Potencial alelopático de Dodonaea viscosa (L.) Jacq. Iheringia Série Botânica, 60 (1), $91-98$.

Ministério da Agricultura e Reforma Agrária. Regras para Análise de Sementes: DNDV/CLAV, 365p.

Ministério da Agricultura, Pecuária e abastecimento. Regras para Análise de sementes:SNDA/DNDU/CLU, 399p.

Ministério da Agricultura, Pecuária e Abastecimento. Secretaria de Política Agrícola, Brasília: Mapa/SPA, 2014. http://www.agricultura.gov.br/comunicacao/noticias/2014/10/safra-de-graos-201415-pode-chegar-a-200-milhoes-de-toneladas.

Paracampo, N. E. N. P., Muller, A. H., Alves, S. de M., Souza Filho, A. P. da S., Guilhon, G. M. S. P., Arruda, M. S. P., Santos, L. da S., \& Arruda, A. C. (2009). Atividade fitotóxica e fungitóxica de extratos de Vouacapoua cf americava Aublet (leg.-caesalp.), essência florestal nativa da amazônia. Revista Brasileira de Ciências Agrárias, 52, 9-22.

Pereira, A. S., Shitsuka, D. M., Parreira, F. J., \& Shitsuka, R. (2018a). Metodologia da pesquisa científica, (1 ${ }^{\mathrm{a}}$. Ed). Santa Maria, RS: UAB/NTE/UFSM. https://repositorio.ufsm.br/bitstream/handle/1/15824/Lic_Computacao_Metodologia-Pesquisa-Cientifica.pdf?sequence=1

Pereira, K. C. L., Oliveira, A. K. M., Matias, R., Rizzi, E. S., \& Rosa, A. C. (2018b). Potencial alelopático do extrato etanólico de Anacardium humile A.St.Hil (cajuzinho-do-cerrado) na germinação e formação de plântulas de Lactuca sativa L. (alface), Lycopersicon esculentum Mill. (tomate) e Senna obtusifolla (L.) Irwin \& Barneby (fedegoso). Gaia Scientia, 12(2), 144-160.

Periotto, F, Perez, S. C. J. G. A., \& Lima, M. I. S. (2004). Efeito alelopático de Andira humilis Mart. Ex Benth na germinação e no crescimento de Lactuca sativa L. e Raphanus sativus L. Acta Botânica Brasílica, 18(3), 425-431.

Pessanha, A. C., Santos, L. M., Freitas, S. P., \& Huziwara, E. (2010). Efeito alelopático de extrato de Schinus Terebinthifolius L. em brachiaria decumbens. XXVII Congresso Brasileiro da Ciência das Plantas Daninhas, Ribeirão Preto - SP.

Reigosa, M. J., Sánchez-Moreiras, A., \& González, L. (1999). Ecophysiological approach in allelopathy. Critical Reviews in Plant Sciences, 18(5), 577-608.

Rice, E. L. (1984). Allelopathy. (2nd ed.), New York, Academic Press.

Rickli, H. C., Fortes, A. M. T., Silva, P. S. S., Pilatti, D. M., \& Hutt, D. R. (2011). Efeito alelopático de extrato aquoso de folhas de Azadirachta indica A. Juss. em alface, soja, milho, feijão e picão-preto. Semina: Ciências Agrárias, 32(2), 473-484.

Rosado, L. D. S., Rodrigues, H. C. A., Pinto, J. E. B. P., Custódio, T. N., Pinto, L. B. B., \& Bertolucci, S. K. V. (2009). Alelopatia do extrato aquoso e do óleo essencial de folhas do manjericão "Maria Bonita" na germinação de alface, tomate e melissa. Revista Brasileira de Plantas. Medicinais, Botucatu, 11, 422428 .

Silva, A. G., \& Carvalho, R. I. N. (2009). Efeito alelopático de extratos de carqueja (Baccharis trimera) e confrei (Symphytum officinale) em sementes e plântulas de girassol. Revista Acadêmica: Ciência Animal, 7(1), 23-32.

Silva, J. S. (2010). Considerações sobre a ocupação do cerrado na microrregião do sudoeste de goiás: modernização versus degradação. Revista em Agronegócios e Meio Ambiente, 3(1), 89-99.

Souza, E. R. B., Almeida, K. S., Camilo, Y. M. V., Marra, G. E. R., Seleguini, A., Naves, R. V., \& Corrêa, G. C. (2010). Avaliação agronômica do cajuzinhodo-cerrado (Anacardium othonianum Rizz.) em Goiás. VII Encontro Nacional de Substratos para Plantas (ENSub), Campo Grande - MS.

Souza, S. A. M., Cattelan, L. V., Vargas, D. P., Piana, C. F. B., Bobrowski, V. L., \& Rocha, B. H. G. (2005). Efeito de extratos aquosos de plantas medicinais nativas do rio grande do sul sobre a germinação de sementes de alface. Publicatio UEPG: Ciências Biológicas e da Saúde, 11(3/4), 29-38.

Souza, V. M., \& Cardoso, S. B. (2013). Efeito alelopático do extrato de folhas de Eucalyptus grandis sobre a germinação de Lactuca sativa L. (alface) e Phaseolus vulgaris L.(feijão). Revista Eletrônica de Educação e Ciência, 3(2), 1-6. 